\title{
Study on Yangzhou Woodcut Prints in the Qing Dynasty
}

\author{
Yiwen Song \\ Eastern International Art College \\ Zhengzhou University of Light Industry \\ Zhengzhou, China
}

\begin{abstract}
Ever since the appearance of woodblock printing in Yangzhou during the Tang Dynasty, the development of Yangzhou woodcut prints has been rapid in Song, Yuan and Ming dynasties, which flourished in the Qing Dynasty. Compared with the previous dynasties, the printing industry of Yangzhou woodcut prints in the Qing Dynasty has more variety a larger scale. As people begin to attach more attention to the artistic value of Yangzhou woodcut prints, therefore this paper carried out an analysis and research on Yangzhou woodcut prints in the Qing Dynasty.
\end{abstract}

Keywords—the Qing Dynasty; Yangzhou; woodcut prints

\section{INTRODUCTION}

Yangzhou has been an important cultural and economic town in Ming and Qing dynasties due to its location at the junction of canal and the Yangtze River. With continuous development of Yangzhou woodcut prints printing technology in the Qing Dynasty, Yangzhou woodcut prints also made a very outstanding achievement, forming a very important part of the history of ancient woodcut prints in China. Yangzhou woodblock printing was renowned throughout the country at that time, the current offset printing in Yangzhou has quite a lot of workshop printing, family printing and official printing copies, on account of its high artistic achievement, it also ranks top in the famous engraving books in our country. Yangzhou is one of the center cities of woodblock printing in Ming and Qing dynasties, also the only city reserving the full range of ancient China's woodblock printing technology. Currently, Yangzhou roughly has a collection of three hundred thousand ancient book copies of Ming and Qing dynasties, in which there are many exquisite woodcut prints. The earliest Yangzhou woodcut prints had a comparatively unique style and remaining quantity, with a relatively distinct artistic style and characteristics, which are possible to well reflect indigenous aesthetic taste.

\section{COMBING OF DEVELOPMENT VEINS OF YANGZHOU WOODCUT PRINTS IN THE QING DYNASTY}

The so-called woodcut prints are mainly an artistic form that uses wood blocks to carry out reverse engraving of a variety of images, then print such prints on paper. Woodcut prints itself has a unique way of knife cutting and aesthetic

CLC: J217 Document Code: A . features, so it has a very high artistic value and status in the history of our ancient art history. Printing is one of the four great inventions of ancient China, which mainly includes image printing and text printing, both select wood because wood materials can be easily drawn, carved, shaped, etc. Woodcut is a form in which image printing is the most prominent and most widely used. A large amount of decorative woodcut prints have been unearthed in wooden funeral chamber tombs of the Han Dynasty in Yangzhou, Xuyi, etc. during the Western Han Dynasty, reflecting the skilled carving skills of woodcut prints in the Western Han Dynasty. There are two types of carving skills of unearthed woodcuts: First, cut straightly with a knife along the picture contour sketched with an ink line beforehand, and then chamfer outside the cutting line to highlight the outline of picture, the spare block needs not to be eradicated. Another technique is flat scraping and carving embossment. The contents of woodcuts include buildings, towers, vehicles and vessels, the sun, moon and stars, drumming entertainment, parade and hunting, etc. At present, the earliest woodcut print in historical records is The Diamond Perfection of Wisdom Sutra in the Tang Dynasty, woodcut prints peaked heydays in the Ming Dynasty after thousands of years of art development and precipitation, during which there were the emergence of multi-color overprinting technique, which was widely used, woodcut prints have become ever more skillful in all aspects of illustrations, engraving and printing. The art of woodcuts represented by Yangzhou woodcut prints was of great prosperity in the Qing Dynasty, with appearance of plentiful court woodcut prints, woodcut New Year pictures and woodcut illustrations, etc. Emperor Shunzhi, Kangxi, Yongzheng and Qianlong in the Qing Dynasty belong to the prosperous times, while Yangzhou woodcut printing art also had vigorous development in this period. At that time, Yangzhou woodcut prints appeared fiction woodcuts, genealogy woodcuts, opera woodcuts, agriculture woodcuts, Buddhism woodcuts and a series of branches, these woodcuts have practiced coloring, exquisite engraving and delicate painting, emerging large numbers of legacy masterpieces, such as Taiping Landscape Painting, Painting of Lingyange Heroes, Lisao Painting, Painting Copybook of Xiying Pavilion, Local Chronicles of Mount Huangshan and other excellent works crowned with eternal glory. The representative of topping woodcuts in Yangzhou woodcuts is Painting Manual of the Mustard Seed Garden, which features variations, fine and powerful lines as well as skilful way of 
cutting, hence the artistic value is extremely high [1]. In the late Qing Dynasty, there appeared more and more social conflicts, Yangzhou woodcut prints were greatly impacted under the turbulent social situation, except for some exquisite Buddhist woodcuts now and then, the remaining fiction woodcuts, genealogy woodcuts, opera woodcuts and agriculture woodcuts all seemed rough, there were rarely masterpieces. Compare with the prosperity and development of woodcut prints in the Ming Dynasty, although Yangzhou woodcut prints had relatively low achievements throughout the Qing Dynasty, some breakthroughs and development were still achieved.

\section{CATEGORIES AND ARTISTIC CHARACTERISTICS OF YANGZHOU WOODCUT PRINTS IN THE QING DYNASTY}

\section{A. Categories of Yangzhou Woodcut Prints in the Qing Dynasty.}

First, book illustrations: book illustration woodcuts in Yangzhou woodcut prints in the Qing Dynasty mainly include the following categories: 1. Buddhist text illustrations: Yangzhou itself is a Buddhist sacred land, the local has numerous temples, thus Buddhist book illustrations occupy a very important position in Yangzhou woodcut prints, the representatives are Deeds of Sakya Tathagata, Guiyuan Mirror, etc.; 2. Local chronicles book illustrations: As a cultural ancient city, Yangzhou has a very rich number of ancient chronicles, the contents of these books are mainly records of the cultural attractions, government offices and buildings and city changes. The various woodcut illustrations in chronicles are very precious, belonging to treasures in our cultural history and art history, the representatives are Illustrated Handbook of Huaiyang Water Conservancy Caption, Jiangdu County Annals, Yangzhou Geography Annals, etc. [2]; 3. Travel book illustrations: The woodcuts of travel book illustrations in Yangzhou woodcut prints in the Qing Dynasty belong to the most splendid part, such Lin Qing's Karma Record of Hongxue, Li Dou's Yangzhou Painting Boats, Zhao Zhibi's Records and Maps of Pingshan House, there were a lot of artists involved in the illustration drawing and engraving of these books, so these travel book illustrations are often exquisite, with very high artistic quality. 4. In addition to the above three categories, Yangzhou book illustration woodcuts in the Qing Dynasty also include some other categories, such as Records and Maps of the World, Selected Climate and Phenology, Illustrated Handbook of Earth, Illustrated Handbook of Vehicle in Book of Diverse Crafts and other illustrating book illustrations in regard to science, architecture, geography, astronomy, etc.; illustrations of Illustrated Handbook of Hangou Old Course Changes in Past Dynasties, Records of Yangzhou Waterways, etc. conducting special introduction to Yangzhou waterway changes in past dynasties [3].

Second, New Year pictures: As a microcosm of the history, the pictures record current affairs with a vivid painting language, providing some figurative references for the study of the history at that time. As an artistic form servicing the public and formed among folk people, the contents of woodcut New Year pictures embody the deep spiritual ballast and pure emotions of the general public, also with strong folk custom and high artistic value: 1. Statue New Year pictures: the main function of statue New Year pictures is for folk sacrifice and worship. Compared with the origin of other New Year pictures, the door-god themes of Yangzhou New Year pictures are less, and military doorgods are also less in the soft and elegant Yangzhou New Year pictures. 2. Good fortune New Year pictures: these New Year pictures mostly have the patterns of "Blessing" and "longevity", gold and doorman, full of goodwill toward one another, five people contending for championship, Zhang Xian archery, heaven-sent sons and other folk tales and legends. Good fortune New Year pictures generally have safeness and longevity, praying for children and good fortune and other well meanings. 3. Historical story New Year pictures: The main contents of historical story New Year pictures are historical stories such as "Wagang Village Heroes", "Stories of the Romance of Sui and Tang Dynasties", "Liangshan 108 Stars of Destiny" etc. that are familiar to people, among which a representative work "Embroidered Portraits of Water Margin Figures" has the highest attainments of historical story New Year pictures. 4. Mundane life New Year pictures: the main theme of these New Year pictures is mundane life, such as the representative work All Kinds of Jobs is one of the New Year pictures works with Yangzhou characteristics, which exerts a very good description of the scenes of business and performances from all walks of life on downtown streets of Yangzhou, which contrast finely with each other and are witty and artful. Therefore, whether viewing from the subject content, or from the technique of expression, Yangzhou woodcut New Year pictures often increase the interestingness of people's living decoration based on different subject matters and different uses, which are widely loved by people.

\section{B. Artistic Characteristics of Yangzhou Woodcut Prints in the Qing Dynasty.}

Firstly, very distinct local features: Yangzhou woodcut prints include very rich varieties, and can well reflect earthly life of Yangzhou characteristics. For example, one of the most important representative in Yangzhou woodcut prints is "painting of showing peep show" in All Kinds of Jobs, which mainly shows the scene of showing peep show in Yangzhou: a child stands on a long bench and watches peep show shown by a man, a woman stands beside the child, and a beggar is begging for money beside the woman. This woodcut print vividly records the scene at that time, with very dense life flavor of Yangzhou.

Secondly, technique of taking advantage of objects to express one's implied meaning and combining calligraphy and painting are applied more: taking advantage of objects to express one's implied meaning and combining calligraphy and painting is an important characteristic of Yangzhou woodcut prints in the Qing Dynasty; people's festive and lucky and beautiful hope at that time can be expressed through this artistic method. For example, "longevity" in woodcut New Year painting includes some story paintings. Very high art level can be reflected through technique of 
combining calligraphy and painting and higher artistic culture and rich imagination of the New Year painting painter can be reflected [4].

Finally, sprightly and beautiful colors: variety, sprightliness and beauty are important color characteristics of Yangzhou woodcut prints. Yangzhou woodcut prints draw the outline of figure and object with a line, and then set multicolor plates in the outline. Although every chromatography possesses smaller picture size, and its distribution is interspersing, main hue commands every painting, and main hue is controlled by using picture size and color depth, then woodcut prints will form very strong color contrast, and reflect higher art level.

\section{VALUE ANALYSIS ON YANGZHOU WOODCUT PRINTS IN THE QING DYNASTY}

As a whole, Yangzhou woodcut prints in the Qing Dynasty possess higher artistic and aesthetical qualities and fully meet the masses' aesthetic needs at that time. As one representative of folk woodcut art, Yangzhou woodcut prints are greatly different from court woodcut prints in aesthetic idea, aesthetic orientation of court woodcut prints is consistent with that of the Qing Dynasty imperial families. Woodcut prints possess characteristics of multifarious carving, gay colors and delicate depiction; while Yangzhou woodcut prints are more consistent with folk aesthetic features in Yangzhou, Yangzhou people's yearn for beautiful life and unsophisticated feeling at that time can be well reflected in Yangzhou woodcut prints, therefore, Yangzhou woodcut prints can fully show then custom and public feelings as well as folk characteristics, with very high artistic value [5]. At the same time, regional characteristics of Yangzhou woodcut prints are stronger in composition layout, application color, line depiction, image modeling, themes and contents and other aspects. Text information and image information in Yangzhou woodcut prints when we research Yangzhou's economy, culture and politics in the Qing Dynasty possesses higher literature value.

\section{CONCLUSION}

In a word, the same with Yangzhou, Yangzhou woodcut prints in the Qing Dynasty also possess characteristics of elegance, exquisiteness, neatness and grace. Woodblock printing industry in Yangzhou rapidly develops due to prosperity of block carving industry in the Qing Dynasty, plus economic development and cultural prosperity in Yangzhou in the Qing Dynasty, therefore, art features and scholar temperament in Yangzhou woodcut prints are very dense, which belongs to an important part of Chinese woodcut prints art. Currently, we should still further research Yangzhou woodcut prints, and allow people to have full understanding in value of Yangzhou woodcut prints.

\section{REFERENCES}

[1] Zhang Hongwei. Woodcut Book Engraving Art in the Ming Dynasty[J]. Journal of Zhengzhou University of Light Industry (Social Science). 2012(06)
[2] Gao Fumin. Peach Blossom Shines and Goes Through Wind And Rain Formation, Development and Evolution of Suzhou Taohuawu New Year Woodblock Prints[J]. Journal of Suzhou College of Education. 2012(01)

[3] Sun Lu. An Observation on Protection and Inheritance of Traditional Handicraft from Yangzhou Woodblock Printing[J]. China Publishing Journal. 2012(16)

[4] Zhou Ju.An Analysis on Secular Values of Buddhist Woodblock Printing in Engraving, Chinese Opera and Novel Illustration in Ming and Qing Dynasties [J]. Arts Criticism. 2012(08)

[5] Li Xia, Wan Yanhua. Productive Protection and Development of Yangzhou Intangible Cultural Heritage "Woodblock Printing"[J]. Urban Development Studies. 2012(05) 